\title{
On a new form of galvanometer for powerful currents
}

\section{Professor C.F. Brackett}

To cite this article: Professor C.F. Brackett (1881) On a new form of galvanometer for powerful currents, Philosophical Magazine Series 5, 11:70, 476-476, DOI: 10.1080/14786448108627047

To link to this article: http://dx.doi.org/10.1080/14786448108627047

巴nublished online: 28 Apr 2009.

Submit your article to this journal ¿

Џll Article views: 2

a

View related articles $₫$ 
ON A NEW FORM OF GALVANOMETER FOR POWERFUL CURRENTS. BY PROFESSOR C. F. BRACKETT, COLLEGE OF NEW JERSEY.

The very powerful currents produced by large dynamo-machines are not easily estimated by the appliances usually found in the physical laboratory.

The various forms of the electro-dynamometer, the cosine-galvanometer, and some other special forms of apparatus may of course be employed with satisfactory results. None of these instruments being in the collection at Princeton, it was determined to construct a galvanometer which should obey the law of tangents and yet not be so large as to be unwieldy. In order to do this, recourse was had to the differential principle. The construction is as follows :-

Two stout hoops of copper or brass of different diameters are very exactly turned in the lathe. They are then each cut open at one point and joined to each other concentrically, by soldering with hard solder, between the ends on one side of the cut, a piece of metal having the same cross section as that of the hoops, and of suitable length. At several other points are inserted between the hoops pieces of hard rubber of proper thickness, which serve to keep them truly concentric.

The free ends of the system thus arranged, and set upright on a proper base-board, are joined to binding-screws.

It will be seen that the differential action on a needle placed at the centre, or on the axis of the hoops pasing through their centre, depends on the different distances of two equal and opposite currents. It is evident also that the instrument may be used as a simple tangent-galvanometer.

Thus, if we call the free ends of the hoops A and B respectively, and the point of juncture $C$, by joining up a circuit through $A$ and $B$ we get the differential action; but by joining up through $\mathrm{C}$ and $\mathrm{A}$ or $\mathrm{B}$, the action is that of a simple tangent-galvanometer. If $r$ and $r^{\prime}$ represent the radii of the outer and inner hoops respectively, the ordinary formula becomes

$$
I=\frac{r r^{\prime}}{2 \pi\left(r-r^{\prime}\right)} \times H \tan d
$$

when the instrument is used differentially.

An instrument has been constructed at the J. C. Green School of Science for its physical laboratory, of dimensions as follows :-

Diameter of outer hoop ....... 10.9 centim.

$\begin{array}{ccc}\text { Diameter of inner hoop } \ldots \ldots \ldots & \mathbf{9} \cdot 96, \\ \text { Width of each hoop } \ldots \ldots \ldots . & 2 \cdot 3 \\ \text { Thickness of each hoop........ } & 0 \cdot 35,\end{array}$

The theoretical constant of this instrument agrees very closely with that ascertained experimentally by means of the voltameter. The needle, which is usually suspended in the centre of the hoops, may, if desired, in order to measure exceedingly powerful currents, be moved along their axis to any required distance on one side. The constant is in that case easily found by an obvious modification of the formula.-Silliman's American Journal, May 1881.

Princeton, March 10, 1881. 